\title{
Radiation Noise Separation of Internal Combustion Engine Based on Gammatone-RobustICA Method
}

\author{
Jiachi Yao, ${ }^{1}$ Yang Xiang, ${ }^{1}$ Sichong Qian, ${ }^{1}$ and Shuai Wang ${ }^{1,2}$ \\ ${ }^{1}$ School of Energy and Power Engineering, Wuhan University of Technology, Wuhan 430063, China \\ ${ }^{2}$ The Second Ship Design Institute of Wuhan, Wuhan 430063, China
}

Correspondence should be addressed to Yang Xiang; yxiang@whut.edu.cn

Received 12 July 2017; Revised 15 October 2017; Accepted 1 November 2017; Published 26 November 2017

Academic Editor: Chao Tao

Copyright (C) 2017 Jiachi Yao et al. This is an open access article distributed under the Creative Commons Attribution License, which permits unrestricted use, distribution, and reproduction in any medium, provided the original work is properly cited.

In the internal combustion engine noise source separation process, the combustion noise and the piston slap noise are found to be seriously aliased in time-frequency domain. It is difficult to accurately separate them. Therefore, the noise source separation method which is based on Gammatone filter bank and robust independent component analysis (RobustICA) is proposed. The 6-cylinder internal combustion engine vibration and noise test are carried out in a semianechoic chamber. The lead covering method is adopted to isolate the interference noise from numbers 1 to 5 cylinder parts, with only the number 6 cylinder parts left bare. Firstly, many mode components of the measured near-field radiated noise signals are extracted through the designed Gammatone filter bank. Then, the RobustICA algorithm is utilised to extract the independent components. Finally, the spectrum analysis, the continuous wavelet time-frequency analysis, the correlation function method, and the drag test are employed to further identify the separation results. The research results show that the frequency of the combustion noise and the piston slap noise are, respectively, concentrated at $4025 \mathrm{~Hz}$ and $1725 \mathrm{~Hz}$. Compared with the EWT-RobustICA method, the separation results obtained by the Gammatone-RobustICA method have very fewer interference components.

\section{Introduction}

The internal combustion engine as power heart is widely used in ships, vehicles, and other means of transportation. With the development of internal combustion engine to heavy load, high speed, and light direction, its vibration noise problem is becoming more and more serious, which has become the main vibration noise source of ships and vehicles. By reducing the level of vibration and noise of the internal combustion engine, the working performance of the internal combustion engine can be improved, and the people's living environment can be ameliorated [1]. In order to draw up the vibration and noise reduction program of the internal combustion engine, the first step is to accurately separate and identify the noise sources of the internal combustion engine. Many parts of the internal combustion engine can produce noise. According to the source of the internal combustion engine, the noise can be divided into mechanical noise, combustion noise, and aerodynamic noise [2-4]. Mechanical noise mainly includes piston slap noise, air valve knock noise, gear meshing noise, and fuel injection pump noise. Combustion noise is caused by the change of the cylinder pressure. Aerodynamic noise includes intake noise, exhaust noise, and fan noise.

Currently, there are many scholars who utilised the cyclic Wiener filtering method [5], blind source separation method [6-8], improved spectrofilter method [9], speed-varying filter [10], and other multichannel methods to separate and identify the noise sources of the internal combustion engine.

When the multichannel method is adopted to separate and identify the noise sources of the internal combustion engine, the multiple channel noise signals of the internal combustion engine need to be measured. However, in the actual engineering test, by the limit of cost and installation conditions, it is necessary to use a few sensors to achieve the same noise source separation effect. Therefore, scholars studied the single channel method to separate and identify the noise sources of internal combustion engine. For example, Zhang et al. [11] adopted the ensemble empirical mode decomposition, the coherent power spectrum analysis, and the 
improved analytic hierarchy process to separate and identify the noise sources of the diesel engine. Bi et al. [12] utilised the EEMD-RobustICA method to separate the combustion noise, piston slap noise, and exhaust noise of the gasoline engine.

When the above single channel method is employed to separate and identify the noise source of the internal combustion engine, the first step is to decompose the single channel noise signal by the EEMD algorithm. However, EEMDbased single channel method has many defects [13-15]. The EMD algorithm lacks rigorous mathematical derivation. The EEMD algorithm is required to add Gaussian white noise before each step of the EMD algorithm. Therefore, the calculation cost of the EEMD algorithm is very large. Moreover, when the EEMD algorithm is applied to decompose the noise signal, the endpoint effect and modal aliasing problems will also exist. In recent years, empirical wavelet transform (EWT) [16], variational mode decomposition (VMD) [17], and the related improved methods are proved to be useful and better tools to decompose the signal. For example, Yao et al. [18] utilised variational mode decomposition and robust independent component analysis to separate the noise source of diesel engine. Moreover, these methods are widely used in bearing fault diagnosis [19-21].

In the real world, the human auditory system can distinguish the mixed speech signals in a noisy environment. At present, there are many scholars establishing the computational auditory scene analysis model and algorithm based on the human ear hearing system to separate and identify the mixed speech signals [22]. The speech signals and the radiated noise signals of the internal combustion engine belong to the separable aliasing sound signals. Thus, the noise source of the internal combustion engine can be separated and identified by the human ear hearing model. Moreover, the Gammatone filter bank is a widely used human ear hearing model [23-26]. Therefore, the Gammatone hearing filter bank can be introduced into the separation and identification of the internal combustion engine noise sources.

In this paper, the lead covering method is utilised to isolate the noise interference from 1 to 5 cylinders, with only the number 6 cylinder part left bare. The WP10-240 sixcylinder four-stroke high speed internal combustion engine vibration and noise test are carried out in a semianechoic chamber. The Gammatone-RobustICA method is proposed to separate and identify the combustion noise and the piston slap noise of the number 6 cylinder.

The paper is organized as follows. In Section 2, basic theory methods (such as the cochlear basement membrane model, the Gammatone filter bank, and the robust independent component analysis) are described. In Section 3, the simulation analysis is carried out. In Section 4, an internal combustion engine noise and vibration test is introduced. In Section 5, separation and identification methods are adopted to separate and identify the noise sources of an internal combustion engine. Finally, Section 6 presents conclusions.

\section{Basic Theory}

2.1. Cochlear Basement Membrane Model of the Auditory System. The human auditory system includes the auditory periphery and the auditory center [27, 28]. The auditory periphery consists of outer ear, middle ear, and inner ear. The inner ear consists of semicircular canal, vestibule, and cochlear implant. The speech signals are through the outer ear, middle ear, and ear bone to the cochlear. The cochlear transforms the mechanical energy of sound waves to neural coding signals and through the auditory nerve into the auditory center. Then the hearing will be produced.

In the auditory system, the cochlear as the human auditory receptor is one of the most important parts. The sound signal processing of the human ear is achieved by the frequency decomposition of cochlear basement membrane. It can not only convert different frequencies of the sound signals into different basement membrane positions, but also switch different sound intensity into different basement membrane vibration amplitude. Thus, the cochlear can complete the coding according to the sound frequency and the sound intensity.

In the auditory model, a set of overlapping band-pass filters' bank is usually used to simulate the cochlear basement membrane. Suppose there are $N$ filters. The $i$ th filter is $h(t, i)$. The response of the basement membrane to the signal $x(t)$ is defined as follows.

$$
y(t, i)=x(t) * h(t, i),
$$

where $y(t, i)$ is the output of the basement membrane. * represented the convolution.

The characteristic of the Gammatone filter bank is highly consistent with the auditory characteristic which can well simulate the basement membrane frequency selectivity and spectral analysis characteristics. Thus, the Gammatone filter bank is widely adopted as the cochlear basement membrane model.

2.2. Gammatone Filter Bank. The Gammatone filter bank is a standard cochlear auditory filter $[29,30]$. It can simulate the band-pass filter characteristics of the basement membrane. The center frequency of each filter is logarithmically evenly distributed on the frequency axis. Suppose the center frequency of the $i$ th filter is $f_{i}$. The time domain expression of the Gammatone filter is

$$
g_{f_{i}}(t)=t^{N-1} \exp (-2 \pi B t) \cos \left(2 \pi f_{i} t+\varphi_{i}\right) u(t),
$$

where $N$ is the filter order. $f_{i}$ is the filter center frequency. $\varphi_{i}$ is the phase of the filter, due to the phase of the sound signals having small influence for hearing; thus the phase $\varphi_{i}$ is usually set as zero. $u(t)$ is the unit step function. $B$ is the attenuation factor of filter. It determines the decay rate of the impulse response which is related to the bandwidth of the filter. The bandwidth of the auditory band-pass filter depends on the center frequency. It usually adopted the equivalent rectangular bandwidth (ERB). The calculation formula is

$$
B=1.019 \operatorname{ERB}\left(f_{i}\right)=1.019\left(24.7+0.108 f_{i}\right) .
$$

The Gammatone filter bank is shown in Figure 1. The time domain waveform under different center frequencies $f_{i}$ is shown in Figure 1(a). The corresponding amplitude frequency response curve is shown in Figure 1(b). 


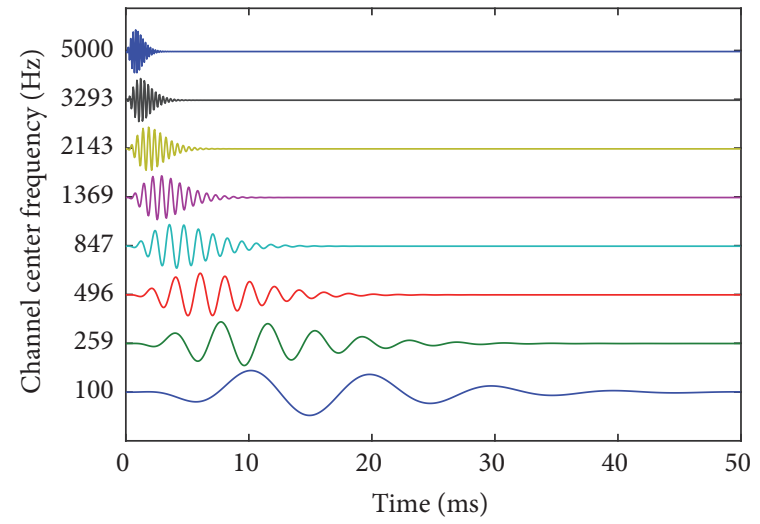

(a) Time domain waveform of Gammatone function

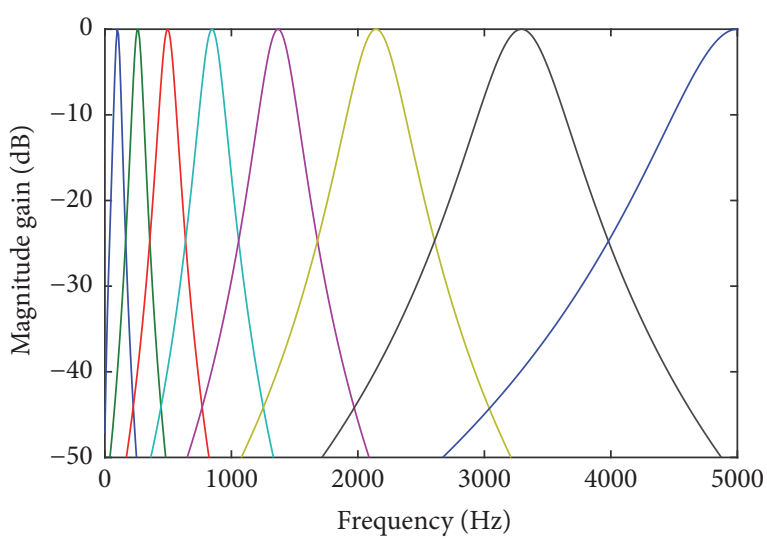

(b) Amplitude frequency response curve of Gammatone function

FIGURE 1: Gammatone filter bank.

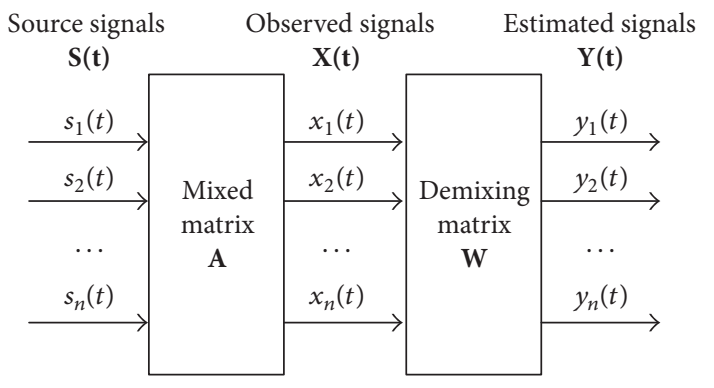

FIGURE 2: A common blind source separation process.

2.3. Robust Independent Component Analysis. The blind source separation method is a powerful signal processing method [31]. It can extract and recover the original signals which cannot be directly observed from several observed mixed signals. Due to the fact that the source signal is unknown and unobserved and the mixed system characteristics are unknown or only a small amount of prior knowledge is known in advance, it is a challenge to use the blind source separation method to separate the source signals.

Suppose the signals collected by the sensors are $x(k)=$ $\left[x_{1}(k), x_{2}(k), \ldots, x_{n}(k)\right]^{T}$. Then it is needed to find an inverse system to reconstruct the original signals $s(k)=$ $\left[s_{1}(k), s_{2}(k), \ldots, s_{n}(k)\right]^{T}$. The output expression is

$$
y(k)=W x(k)=W A s(k) .
$$

A common blind source separation process is shown in Figure 2.

The independent component analysis (ICA) is an important method to solve the blind source separation problems. The FastICA algorithm is a widely used blind source separation algorithm which is proposed by the Hyvärinen [32]. The FastICA algorithm has high convergence speed and reliability. It is cubic convergence. However, it has some limitations. When the source signal spatial correlation is high, the FastICA algorithm will have not good separation results, and the kurtosis based on higher order cumulant has its own defects in the field value. To solve these problems, Zarzoso and Comon [33] proposed the RobustICA algorithm which has excellent blind source separation effect. The RobustICA algorithm utilised the kurtosis as the objective function. The kurtosis is an indicator to evaluate the non-Gaussian characteristic of the analysed signal. The kurtosis is defined as

$$
\operatorname{kurt}(y)=\frac{E\left\{|y|^{4}\right\}-2 E^{2}\left\{|y|^{2}\right\}-\left|E\left\{y^{2}\right\}\right|^{2}}{E^{2}\left\{|y|^{2}\right\}}
$$

Suppose the observed signal is $X$. The RobustICA algorithm does not need to carry out the whitening process for the observed signal. It only requires the mean value of the observed signal which is zero. By RobustICA algorithm, the unmixed signal is $y=w^{T} X$. The specific calculation process of the RobustICA algorithm is shown as follows.

Step 1. Counter $n=1$. Suppose the number $N$ of source signals is the same with the number of observed signals.

Step 2. $w_{n}$ is randomly assigned as the initial value $w_{n}(0)$ and the norm is 1 . The number of iteration steps $k$ is set as 1 .

Step 3. Calculate the polynomial $p(\mu)=\sum_{k=0}^{4} a_{k} \mu^{k}$. The largest root of the objective function is obtained. The calculation formula is $\mu_{\mathrm{opt}}=\operatorname{argmax}_{\mu}|k(w+\mu g)|$.

Step 4. Update the separation matrix $w_{n}^{+}(k)=w_{n}(k-1)+$ $\mu_{\text {opt }} g$. And normalize $w_{n}(k)=w_{n}(k) /\left\|w_{n}(k)\right\|$.

Step 5. Repeat Steps 3 and 4 until the $\left|w_{n}(k)^{T} w_{n}(k-1)\right|$ is sufficient and less than 1.

Step 6. Orthogonal $w_{n}^{+}=w_{n}-W W^{T} w_{n}^{+}$. Normalize $w_{n}(k)=$ $w_{n}(k) /\left\|w_{n}(k)\right\|$.

Step 7. Make $n=n+1$. Then go back to Step 2 for next iteration until $n=N$. 


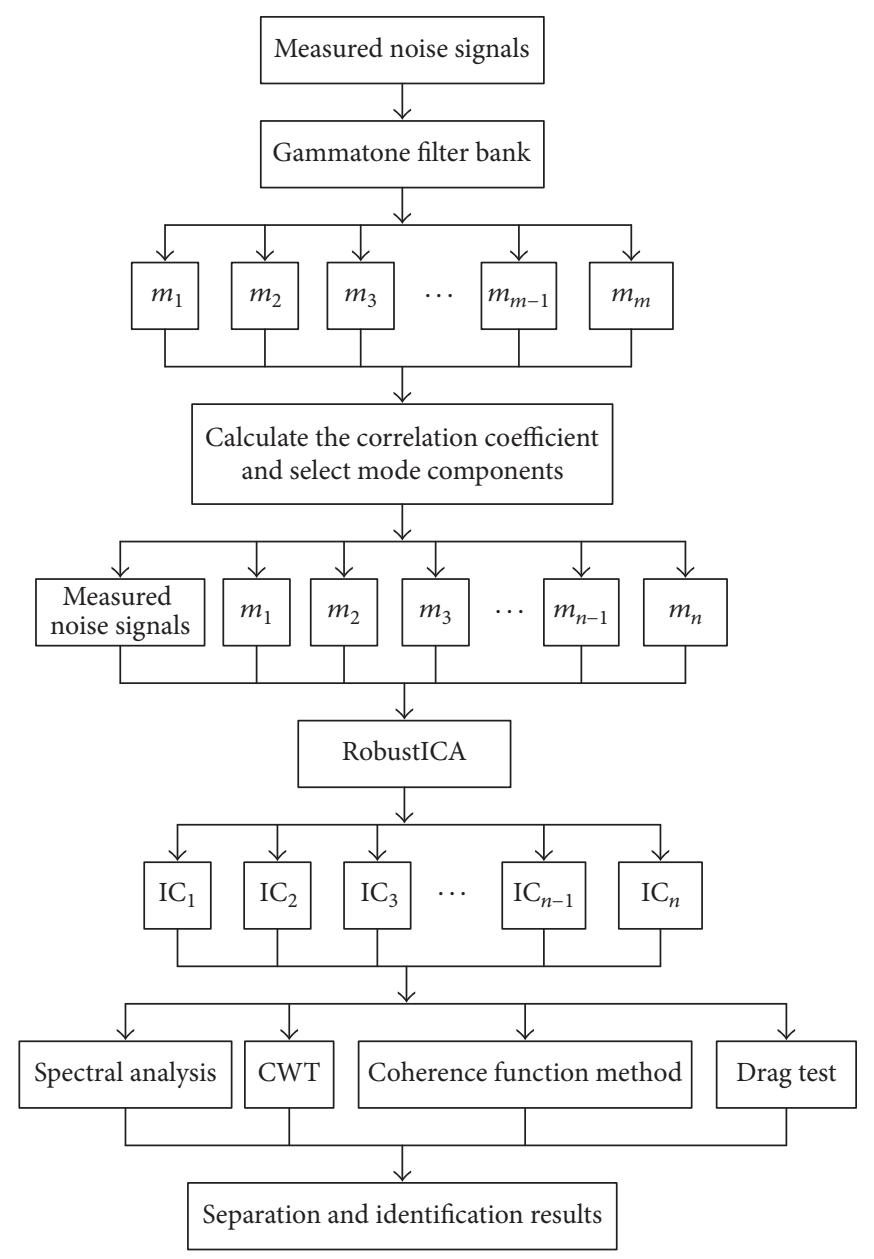

Figure 3: Calculation flow of the Gammatone-RobustICA method.

2.4. Calculation Process of Gammatone-RobustICA Method. For the measured single channel radiated noise signals, the Gammatone-RobustICA method is utilised to separate and identify the noise sources. First, the different mode components of the measured signals are extracted by the Gammatone filter bank. Because these different mode components are not always independent of each other, thus the blind source separation technique is still needed to further deal with the separated signal components to extract the independent components. Then the correlation coefficient between the mode components and the measured signal is calculated. The mode components which have a higher correlation coefficient with the measured signal are retained. The retained mode components and the measured signal are combined together to form a new signal group. The RobustICA algorithm is used to extract the independent components. Finally, the obtained separation results are further identified through the spectral analysis, the continuous wavelet transform (CWT), the coherence function method, and the drag test of internal combustion engine. The calculation flow of the Gammatone-RobustICA method is shown in Figure 3.

\section{Simulation Analysis}

In order to illustrate the performance of the GammatoneRobustICA method, some typical signals are selected to carry out the simulation analysis by MATLAB. The selected typical signals $(S 1, S 2$, and $S 3)$ are shown as follows.

$$
\begin{aligned}
& S 1=\cos (2 \pi \cdot 49 \cdot t) \\
& S 2=\cos (2 \pi \cdot 115 \bullet t) \\
& S 3=\cos (2 \pi \cdot 201 \bullet t) \\
& S=S 1+S 2+S 3 .
\end{aligned}
$$

The sampling frequency of the selected signals is $3000 \mathrm{~Hz}$, and the sampling number of the signals is 300 . The time domain waveform of the selected source signals is shown in Figure 4.

For the mixed signal $S$, the Gammatone-RobustICA method and the EWT-RobustICA method are, respectively, utilised to separate the selected source signals $S 1, S 2$, and $S 3$.

When using the Gammatone-RobustICA method, the frequency range of the Gammatone filter bank is set to 


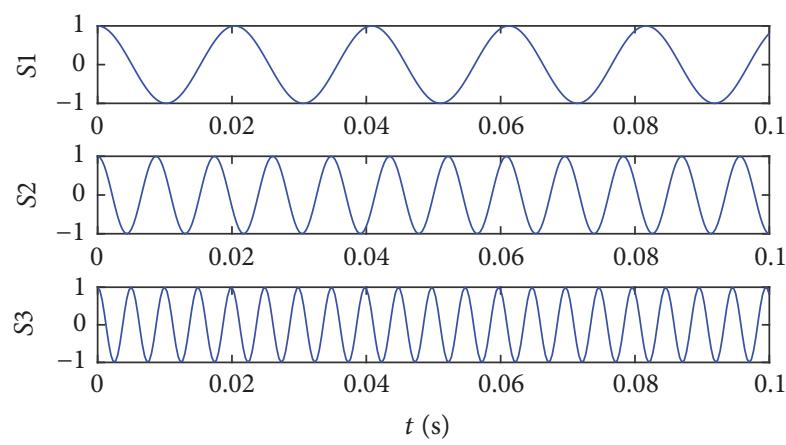

Figure 4: Time domain waveform of the selected source signals.
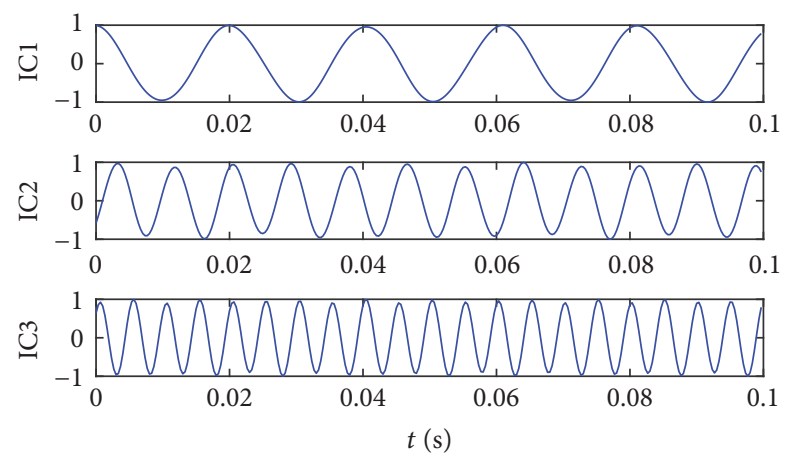

(a) Separation results of the Gammatone-RobustICA method
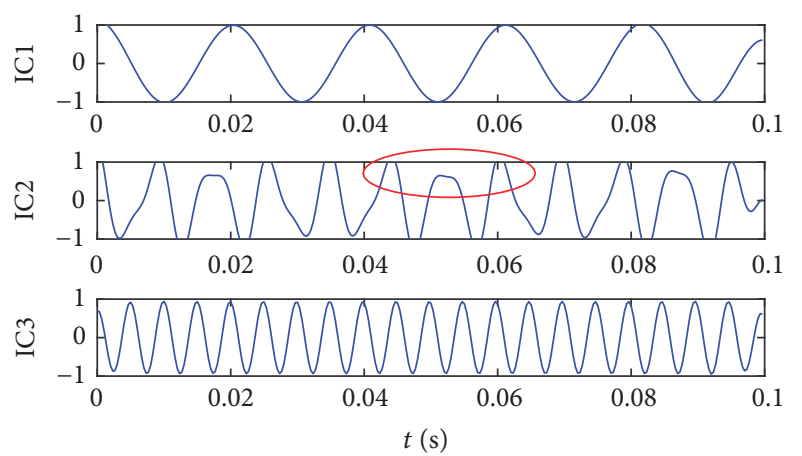

(b) Separation results of the EWT-RobustICA method

Figure 5: Comparison of simulation signal separation results.

$45 \mathrm{~Hz}-205 \mathrm{~Hz}$, and the channel number is set to 3 . By the Gammatone filter bank, the three mode components of the mixed signals can be extracted. Then the RobustICA algorithm is adopted to further extract the independent components from the three mode components. The separation results of Gammatone-RobustICA method are shown in Figure 5(a).

From Figures 4 and 5(a), it can be seen that the IC1, IC2, and IC3 are, respectively, corresponding to $S 1, S 2$, and $S 3$. The results obtained by Gammatone-RobustICA method are similar to the time domain waveforms of the source signals.

When using EWT-RobustICA method, the separation results of EWT-RobustICA method are shown in Figure 5(b). From Figures 4 and 5(b), it can be seen that IC1, IC2, and IC3 are, respectively, corresponding to $S 1, S 2$, and $S 3$. But
TABLE 1: Specific parameters of the WP10-240 type diesel engine.

\begin{tabular}{lc}
\hline Characteristics & Parameters \\
\hline Engine type & In-line engine \\
Cylinder number & 4 \\
Stroke number & 6 \\
Cylinder diameter $\times$ stroke & $126 \mathrm{~mm} \times 130 \mathrm{~mm}$ \\
Firing order & $1-5-3-6-2-4$ \\
Maximum output power & $175 \mathrm{~kW}$ \\
Rated power speed & $2200 \mathrm{rpm}$ \\
Compression ratio & $17: 1$ \\
Maximum torque & $1000 \mathrm{~N} \cdot \mathrm{m}$ \\
Maximum torque speed & $1200-1600 \mathrm{rpm}$ \\
\hline
\end{tabular}

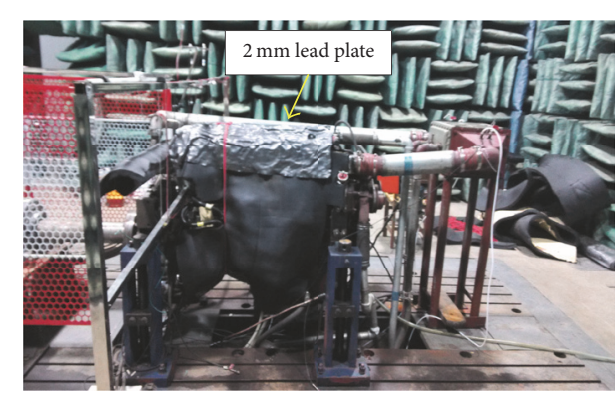

FIGURE 6: Lead cover of the internal combustion engine.

the IC2 has some difference with the $S 2$. This can be seen from the red circle in Figure 5(b). Thus, it can be considered that Gammatone-RobustICA method has a better separation effect than EWT-RobustICA method.

\section{Experimental Investigation}

4.1. Test Platform. The noise and vibration test of internal combustion engine are carried out in a fully enclosed semianechoic chamber. The size of the semianechoic chamber is length $7.04 \mathrm{~m} \times$ width $6.79 \mathrm{~m} \times$ height $5.95 \mathrm{~m}$. The free sound field radius is not less than 2 meters, and the background noise is $18 \mathrm{~dB}$.

Test bench contains the WP10-240 type high speed diesel engine, transmission shaft, Germany's Siemens 1PL6 AC motor, console, and other related accessories. The specific parameters of the WP10-240 type high speed diesel engine are shown in Table 1.

The internal combustion engine has six cylinders. It will produce many vibration and noise sources. It is very difficult to directly separate all the noise sources of the internal combustion engine. Therefore, the lead covering method is utilised to isolate the noise from the numbers $1-5$ cylinders, and only the number 6 cylinder parts are exposed. The noise source of the specified number 6 cylinder is separated and identified. The lead cover of the internal combustion engine is shown in Figure 6.

4.2. Test Conditions. The internal combustion engine is normally operated at a rated speed of $2200 \mathrm{rpm}$. Thus, it is necessary and meaningful to separate and identify the noise 


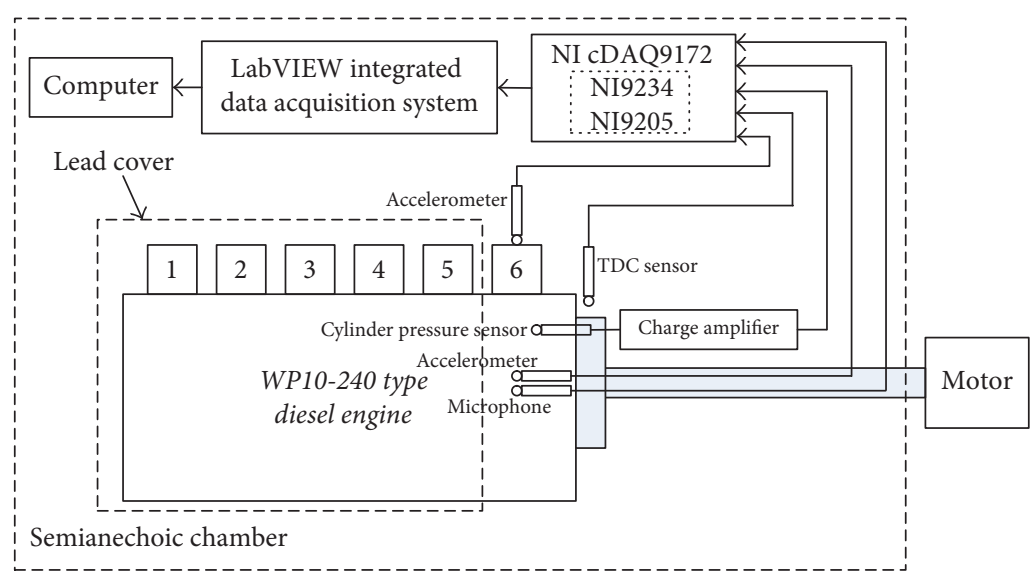

FIGURE 7: Vibration and noise measuring system of internal combustion engine.

TABLE 2: Internal combustion engine test conditions.

\begin{tabular}{lccc}
\hline & Test conditions & Speed (rpm) & Percentage of load (\%) \\
\hline$(1)$ & Normal condition & 2100 & 0 \\
$(2)$ & Drag condition & 2100 & 0 \\
\hline
\end{tabular}

sources of the internal combustion engine at the rated speed. However, in the internal combustion engine test bench, the coupling equipment of the internal combustion engine has some problems. The internal combustion engine cannot reach the rated speed. In the test, the actual speed of the internal combustion engine is $2100 \mathrm{rpm}$.

Moreover, when the internal combustion engine is in drag condition, the internal combustion engine will not produce the combustion noise and will only produce the mechanical noise. However, it is difficult to measure the independent piston slap noise because many moving parts of an internal combustion engine will produce noise. According to the relevant knowledge of internal combustion engine, when the piston impacts the inner wall of the cylinder, it will produce the vibration, and then the vibration will further produce piston slap noise. Thus the frequency of the piston slap vibration can be utilised to assess the accuracy of the separated piston slap noise. The test conditions of internal combustion engine are shown in Table 2.

4.3. Measuring System and Measuring Point Arrangement. The vibration and noise measuring system of internal combustion engine is shown in Figure 7. The measuring system includes the NI 9234 and NI 9205 acquisition module that the highest sampling rate can be up to $51.2 \mathrm{kHz}$. The LC0158T accelerometers are adopted to measure the cylinder head vibration and the piston slap vibration that the sensitivity is $30 \mathrm{mV} / \mathrm{g}$, the range is $166 \mathrm{~g}$, and the frequency range is $0-15 \mathrm{kHz}$. The type of the cylinder pressure sensor is Kistler $7013 \mathrm{C}$ that the range is $25 \mathrm{MPa}$, with a single channel charge amplifier 5018A1000. The DGO9767CD electret microphone is applied to measure the noise signals that the sensitivity is $50 \mathrm{mV} / \mathrm{Pa}$, and the frequency response range is $20 \mathrm{~Hz}-20 \mathrm{kHz}$.

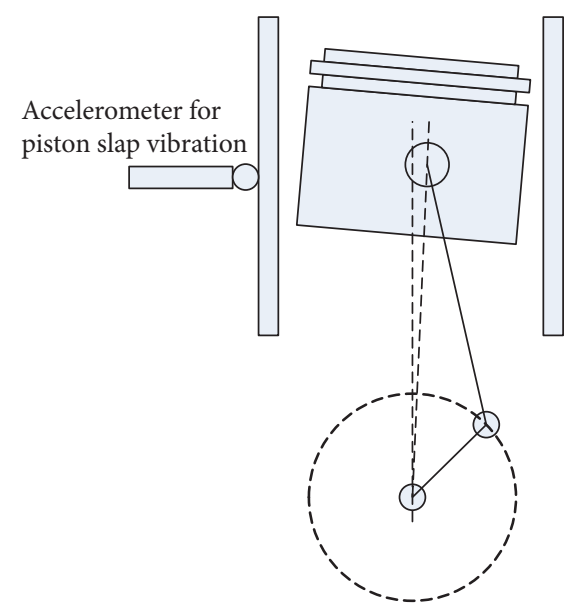

FigURE 8: Measured position of piston slap vibration.

In fact, due to the limitation of the test conditions, it is difficult to measure the independent combustion noise. According to the related knowledge of internal combustion engine, the combustion noise is related to the drastic change of cylinder pressure. Drastic change of cylinder pressure can cause vibration of cylinder head and body surface, and then the vibration will produce the combustion noise. Thus, the correlation function of cylinder pressure and cylinder head vibration can be used to determine the frequency of the combustion noise and then further evaluate the accuracy of separated combustion noise.

Due to the fact that the structure of internal combustion engine and movement trajectory of piston are known before, thus the place of the piston slap occurring can be determined according to the structure of internal combustion engine and movement trajectory of piston. The measured position of the piston slap vibration is corresponding to the position that the piston impacts the inner wall of the cylinder. The measured position of the piston slap vibration is shown in Figure 8.

The DGO9767CD electret microphone is arranged at $1 \mathrm{~cm}$ distance away from the number 6 cylinder body side. The LC0158T accelerometer is arranged at the piston slap place 


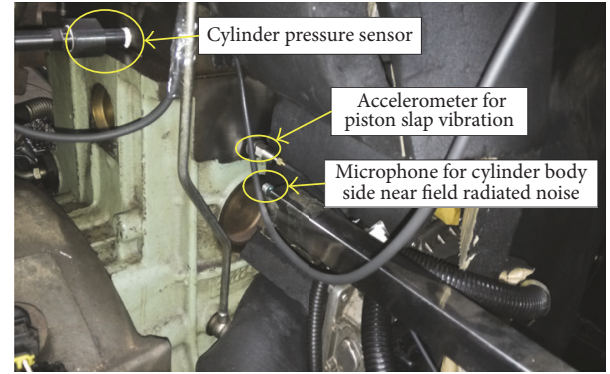

FIGURE 9: Specific arrangement of the measuring point.
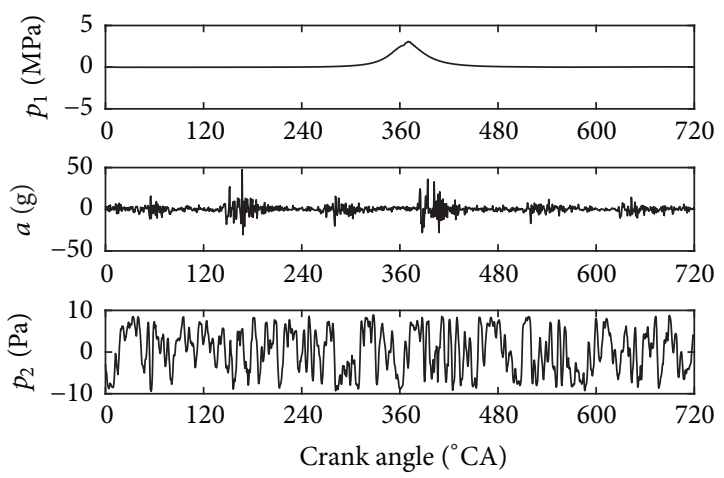

Figure 10: Cylinder pressure, cylinder head vibration acceleration, and cylinder body side near-field radiated noise signals.

to measure the piston slap vibration when the internal combustion engine is in drag condition. The specific arrangement of measuring point is shown in Figure 9.

In the test, the highest frequency of the internal combustion engine radiated noise is below $8000 \mathrm{~Hz}$. According to the sampling theorem, the sampling frequency is greater than twice the highest frequency of the analysed signals. Thus, the sampling frequency can be set to $25.6 \mathrm{kHz}$.

The number 6 cylinder is set as the research object. When the internal combustion engine is in $2100 \mathrm{rpm}$ and noload condition, the cylinder pressure signals $\left(p_{1}\right)$, cylinder head vibration acceleration signals $(a)$, and the cylinder body side near-field radiated noise signals $\left(p_{2}\right)$ are measured. It is shown in Figure 10.

\section{Separation and Identification of the Near-Field Radiated Noise}

In this part, the Gammatone-RobustICA method and the EWT-RobustICA method are, respectively, used to separate and identify the noise sources of the cylinder body side nearfield radiated noise.

In the process of the noise and vibration test, the measured noise signal may have random error components which will affect the subsequent calculation results. In order to reduce the random error components, the pretreatment such as eliminate trend items and slip average is carried out on the measured noise signal. The preprocessed noise signal is shown in Figure 11.

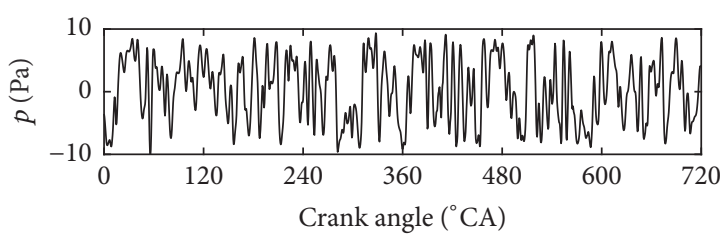

FIGURE 11: Preprocessed noise signal.

5.1. Gammatone-RobustICA Method. When the Gammatone-RobustICA method is utilised to separate and identify the noise source of the internal combustion engine, the first step is to design an appropriate Gammatone filter bank to extract various mode components of the preprocessed noise signal. It is necessary to predefine the two important parameters of the Gammatone filter bank, the center frequency range, and the number of channels. For the center frequency range, on the one hand, the frequency range of human audible sounds is $20 \mathrm{~Hz}-20 \mathrm{kHz}$. On the other hand, the frequency range of the internal combustion engine radiated noise is usually below $8000 \mathrm{~Hz}$. Thus, the center frequency of the Gammatone filter bank is set to $20 \mathrm{~Hz}-8000 \mathrm{~Hz}$. For the number of channels of the Gammatone filter bank, on the one hand, considering the calculation accuracy and the computing costs, the higher the number of channels is, the higher the accuracy of the calculation is, and the higher the cost of the computation is; thus the number of channels of the Gammatone filter bank should not be too much. On the other hand, according to the related knowledge of internal combustion engine, the noise sources of internal combustion engine are combustion noise, piston slap noise, air valve knock noise, gear meshing noise, fuel injection pump noise, and so forth. After considering these factors, the number of channels of the Gammatone filter bank is set to 11 .

By the Gammatone filter bank, the mode components from the preprocessed noise signal can be obtained. The decomposition results are shown in Figure 12.

In order to improve the efficiency of the calculation, the mode components with large correlation with the preprocessed noise signal need to be selected to carry out the next step calculation.

Suppose the correlation coefficient between the mode components and the preprocessed noise signal is $r_{i}(i=$ $1,2, \ldots, n) ; n$ is the number of the mode components. Correlation coefficient $r$ is defined as follows.

$$
r_{X Y}=\frac{\operatorname{cov}(X, Y)}{\sqrt{D(X)} \sqrt{D(Y)}},
$$

where $X$ represents the source signal. $Y$ represents the separation component. $\operatorname{cov}(X, Y)$ represents the covariance of $X$ and $Y . D(X)$ and $D(Y)$ represent the variance of $X$ and $Y$, respectively.

According to Pearson correlation coefficient theory [34], the correlation coefficient is in the range of -1 to +1 . If the correlation coefficient is greater than zero, there is a positive correlation between the two variables. On the contrary, there is a negative correlation. In general, if the correlation coefficient is greater than 0.3 , the two variables are correlated. 


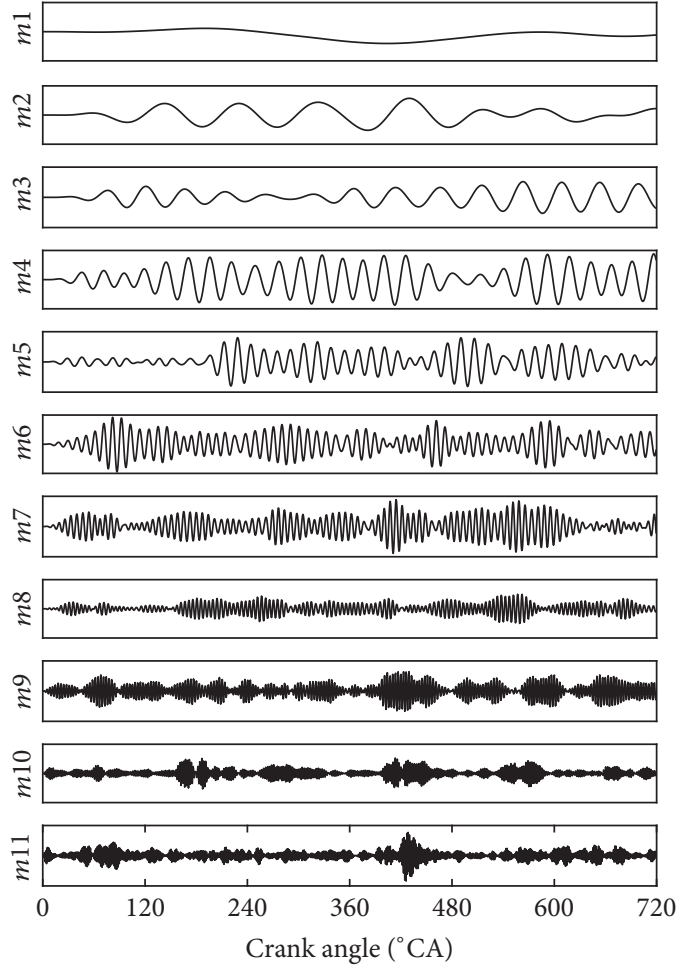

Figure 12: Decomposition results by the Gammatone filter bank.

In order to select the mode components, the threshold $\lambda$ is set to determine whether the mode component is retained or not. But the internal combustion engine has many noise sources, and there are many noise disturbances in the measurement process. Thus, if the threshold of the correlation coefficient is set to 0.3 , the selected mode components will be less, and the separated independent noise source information will not be sufficient. In order to obtain more sufficient independent noise source information, in the actual study the threshold of the correlation coefficient needs to be set smaller. Here, the threshold of the correlation coefficient is defined as follows.

$$
\lambda=\frac{\max \left(r_{i}\right)}{\eta}, \quad i=1,2, \ldots, n,
$$

where $\eta$ is the ratio factor and $\eta$ is set to 10.0 .

The calculation results of the correlation coefficient between the mode components and the preprocessed noise signal are shown in Table 3.

From Table 3, it can be seen that the maximum correlation coefficient is 0.1256 . Thus, if the correlation coefficient is more than 0.01256 , it should be retained. On the contrary, if the correlation coefficient is less than 0.01256 , it should be taken out. Through analysing, it can be determined that $m 2$, $m 3, m 4, m 5, m 6, m 7, m 9$, and m11 should be retained, and $m 1$, $m 8$, and $m 10$ should be taken out.

Due to the fact that the retained mode components are not always independent of each other, the RobustICA algorithm needs to be used to extract the independent components. The retained mode components and the preprocessed
TABLE 3: Correlation coefficient between the mode components and the preprocessed noise signal.

\begin{tabular}{lc}
\hline Mode components & Correlation coefficient \\
\hline$m 1$ & 0.0001 \\
$m 2$ & $\mathbf{0 . 0 9 2 5}$ \\
$m 3$ & $\mathbf{0 . 0 9 8 7}$ \\
$m 4$ & $\mathbf{0 . 0 9 0 3}$ \\
$m 5$ & $\mathbf{0 . 0 5 3 9}$ \\
$m 6$ & $\mathbf{0 . 1 2 5 6}$ \\
$m 7$ & $\mathbf{0 . 0 9 0 2}$ \\
$m 8$ & 0.0011 \\
$m 9$ & $\mathbf{0 . 0 3 9 2}$ \\
$m 10$ & 0.0098 \\
$m 11$ & $\mathbf{0 . 0 2 1 5}$ \\
\hline
\end{tabular}
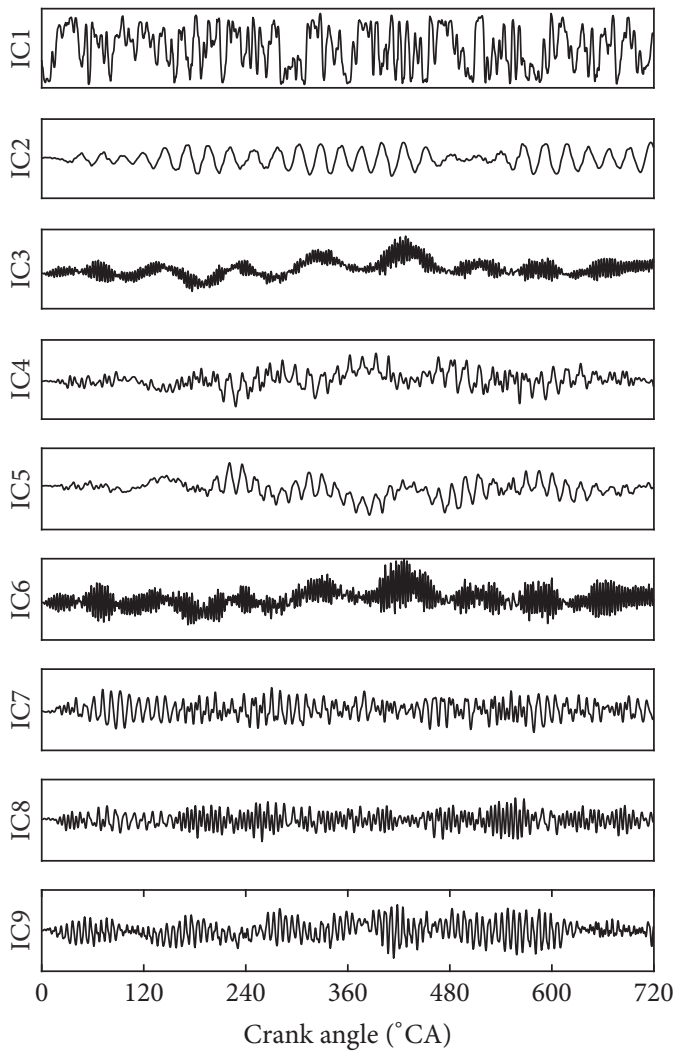

FIGURE 13: RobustICA calculation results.

noise signal are combined together to form a new signal group. Then the RobustICA algorithm is employed to extract the independent components. The calculation results are shown in Figure 13.

According to the relevant knowledge of internal combustion engine, the fuel combustion in the cylinder can cause drastic pressure change in the cylinder, and it caused the combustion noise. Thus the combustion noise is high frequency signal. Through analysing the nine components, the IC6 is the high frequency signal. Thus it can be preliminarily judged that the IC6 component is the combustion noise. 
The mechanical noise of internal combustion engine is usually below $3500 \mathrm{~Hz}$ [35]. Through analysing the RobustICA calculation results, the frequency of IC9 is below $3500 \mathrm{~Hz}$. Thus it can be preliminarily judged that the IC9 component is the piston slap noise.

Apart from IC6 and IC9, as for the rest 7 components, they may be the air valve knock noise, gear meshing noise, fuel injection pump noise, or other noise sources. Ideally, all the noise sources of the internal combustion engine should be separated and identified. However, since the noise sources are seriously mixed with each other, it is difficult to separate and identify all the noise sources, and they need further research. For example, the air valve knock noise is mainly caused by the impact of valve opening and closing, and timing of valve opening and closing can be determined according to the timing of inlet and exhaust of internal combustion engine. Moreover, through arranging the vibration sensor and the acoustic sensor near the valve, and combining the timing of valve opening and closing, the air valve knock noise can be further studied. The gear meshing noise is generated by the collision and friction between teeth during the gear meshing process. Every turn of the gear can produce the collision and friction; thus the gear meshing noise can be further studied. The fuel injection pump noise is mainly caused by the oil pressure change during the oil spraying process. The fuel injection pump noise can be studied through oil injection pressure and burning time of internal combustion engine.

Considering that combustion noise and piston slap noise are the main noise sources of internal combustion engine, thus the paper is mainly on the separation and identification of combustion noise and piston slap noise.

The FFT (Fast Fourier Transform) and CWT (Continuous Wavelet Transform) are combined to further identify the separation results. The calculation results are shown in Figures 14 and 15. The correlation function of cylinder pressure and cylinder head vibration is shown in Figure 16.

From Figure 14, it can be seen that the frequency of IC6 component focuses on $4025 \mathrm{~Hz}$, and the time domain waveform of IC6 component has great change at $390^{\circ} \mathrm{CA}$. From Figure 14(c), the frequency energy is large around the $390^{\circ} \mathrm{CA}$, and it is mainly concentrated around $4000 \mathrm{~Hz}$. According to the prior knowledge of the internal combustion engine, the ignition sequence of the internal combustion engine is 1-5-3-6-2-4. The ignition angle of the number 6 cylinder is around $390^{\circ} \mathrm{CA}$. Due to the fact that the number 1-5 cylinders are covered by lead, the frequency energy of the number 6 cylinder is bigger than the number 1-5 cylinders. Moreover, from Figure 16, cylinder pressure and cylinder head vibration have a good correlation near $4000 \mathrm{~Hz}$. The combustion noise is mainly caused by the change of cylinder pressure. Near $4000 \mathrm{~Hz}$, the main information about combustion noise is included. Thus, it can be determined that the IC6 component is the combustion noise.

From Figure 15, it can be seen that the frequency of IC9 component focuses on $1725 \mathrm{~Hz}$. Combined with Figure 16, the correlation function of cylinder pressure and cylinder head vibration is not good near $1725 \mathrm{~Hz}$. From Figure 15(c), the frequency energy is huge around the $390^{\circ} \mathrm{CA}$. It is

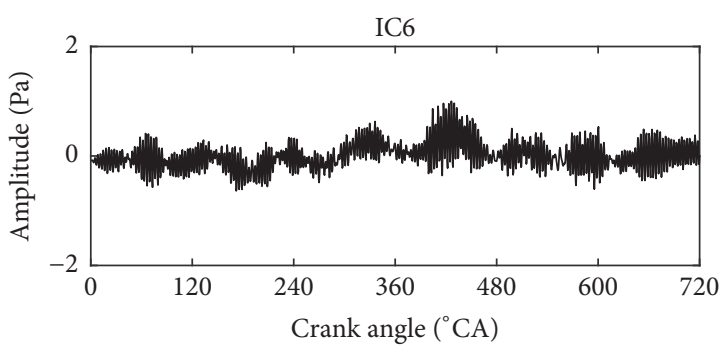

(a) Time domain waveform

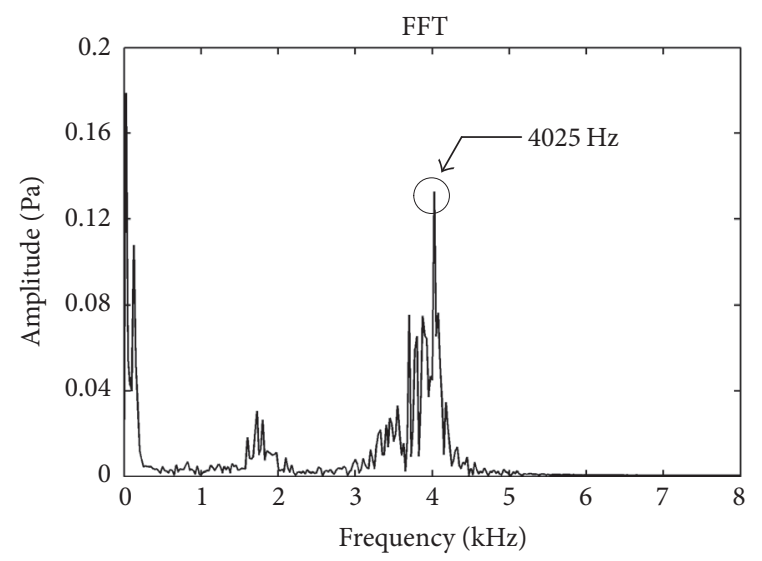

(b) FFT

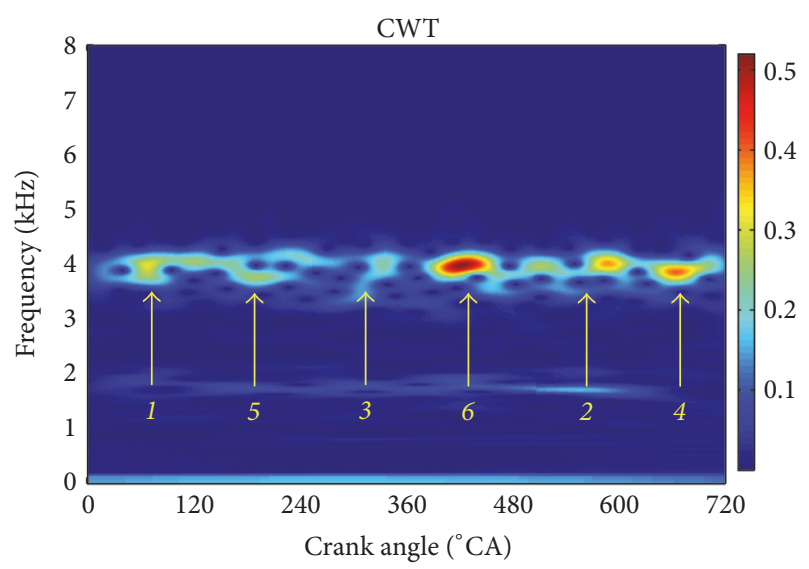

(c) $\mathrm{CWT}$

FIGURE 14: Time domain waveform, FFT, and CWT of IC6 by the Gammatone-RobustICA method.

corresponding with the ignition angle of the number 6 cylinder. In order to further confirm the noise component of the IC9, the internal combustion engine drag test is carried out. By the drag test, the piston slap vibration signal is measured separately. The FFT of IC9 and piston slap vibration is shown in Figure 17. From Figure 17, the IC9 spectrum is very consistent with the piston slap vibration spectrum. Combined with Figure 18, correlation function of IC9 can be seen and piston slap vibration is basically greater than 0.5, and therefore it can be considered that IC9 and piston slap vibration have a good correlation. Thus, it can be determined that the IC9 component is mainly the piston slap noise. 


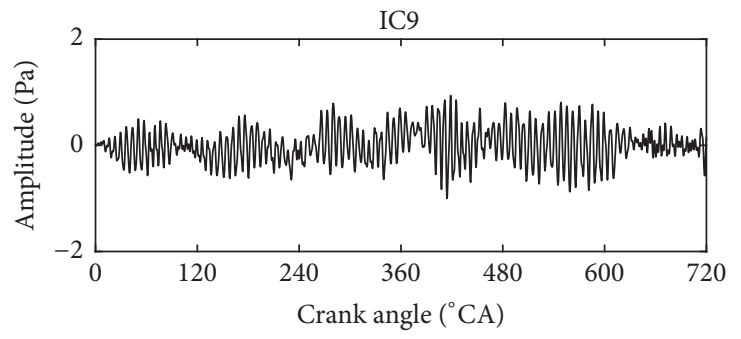

(a) Time domain waveform

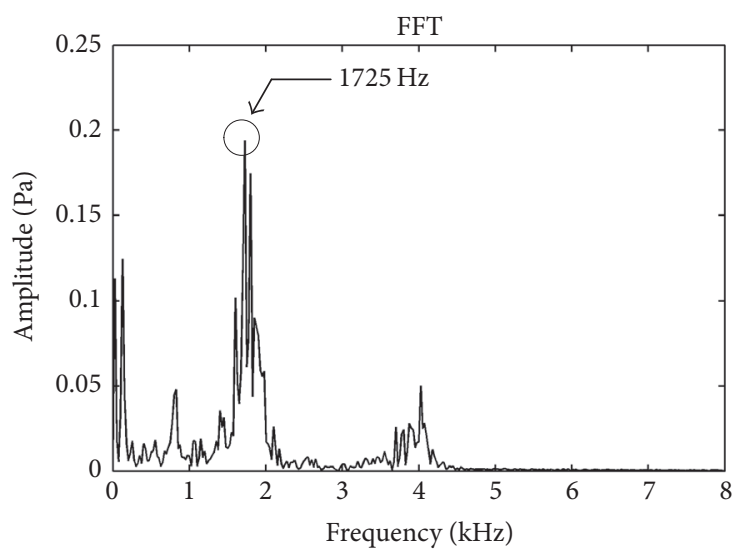

(b) FFT

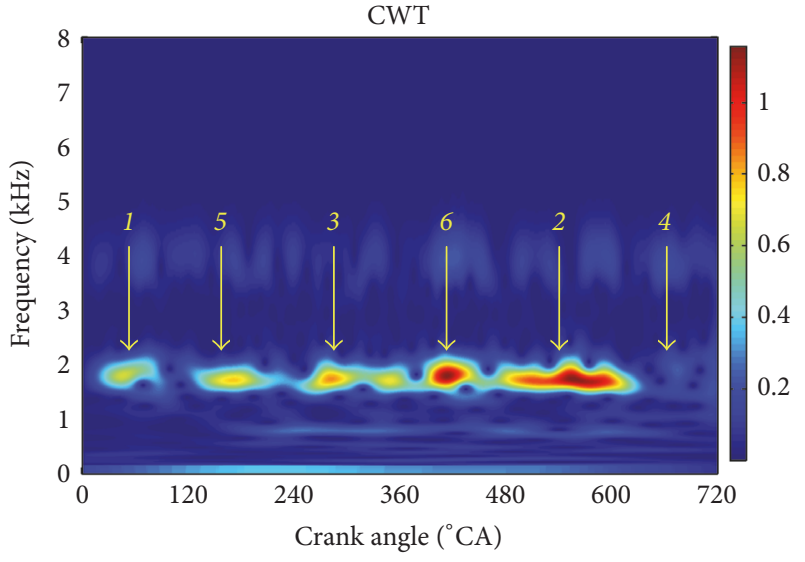

(c) CWT

FIgUre 15: Time domain waveform, FFT, and CWT of IC9 by the Gammatone-RobustICA method.

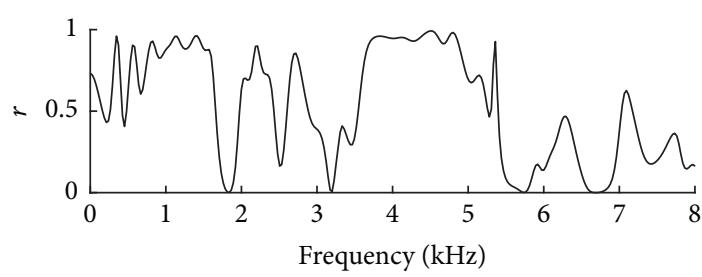

FIgURE 16: Correlation function of cylinder pressure and cylinder head vibration.

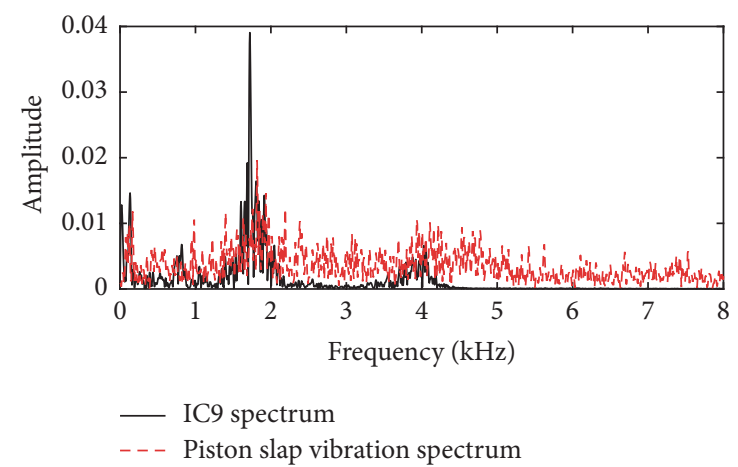

FIGURE 17: FFT of IC9 and piston slap vibration.

5.2. EWT-RobustICA Method. In this part, the EWT-RobustICA method is used to separate the noise source of internal combustion engine. Firstly, the EWT algorithm is applied

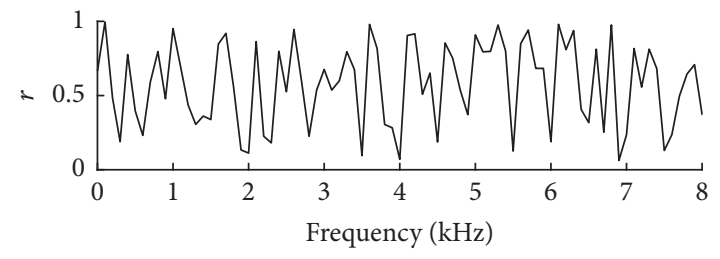

FIGURE 18: Correlation function of IC9 and piston slap vibration.

to decompose the preprocessed noise signal. The calculation results are shown in Figure 19.

After the preprocessed noise signal is decomposed by the EWT algorithm, empirical modal components can be obtained. But it may have some false empirical modal components. Thus, it is necessary to remove the false empirical modal components. Hence, the correlation coefficient between empirical modal components and preprocessed noise signal is utilised to determine whether the empirical modal component is removed or not. The correlation coefficient between empirical modal components and preprocessed noise signal is shown in Table 4 .

From Table 4, it can be seen that the maximum value of the empirical modal components is 0.8532 . Thus, if the empirical modal components are less than 0.08532, it should be removed. Therefore, F3, F4, F5, F6, F7, F8, and F9 should be removed. Then the remaining $F 1$ and $F 2$ and the preprocessed noise signal are combined together to form a new signal group. The RobustICA algorithm is utilised to extract the 


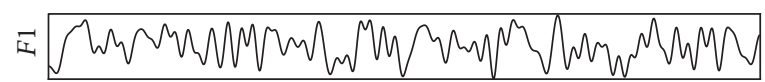

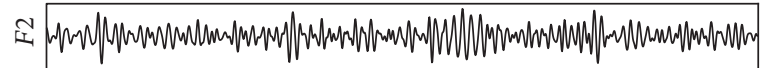
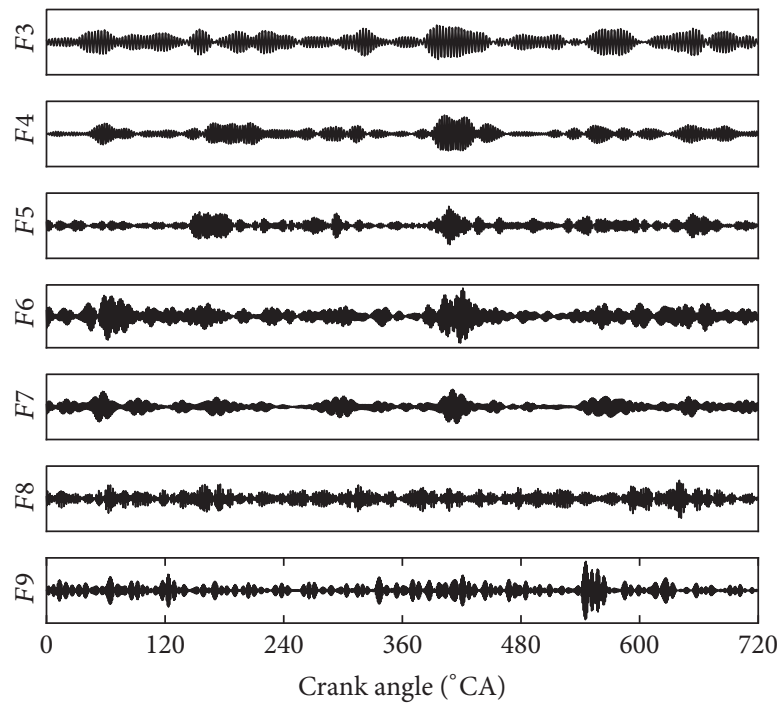

FIGURE 19: EWT calculation results.

TABLE 4: Correlation coefficient between empirical modal components and preprocessed noise signal.

\begin{tabular}{lc}
\hline Empirical modal components & Correlation coefficient \\
\hline F1 & $\mathbf{0 . 8 5 3 2}$ \\
F2 & $\mathbf{0 . 5 1 4 4}$ \\
F3 & 0.0712 \\
F4 & 0.0569 \\
F5 & 0.0525 \\
F6 & 0.0214 \\
F7 & 0.0146 \\
F8 & 0.0159 \\
F9 & 0.0071 \\
\hline
\end{tabular}

independent components. The RobustICA calculation results are shown in Figure 20.

By analysing, it can be preliminarily judged that the IC1 component and the IC2 component are the combustion noise and the piston slap noise. Then the FFT and CWT are utilised to further analyse the IC1 component and the IC2 component. The calculation results are shown in Figures 21 and 22 .

From Figure 21, it can be seen that the amplitude of ICl component has great change around $390^{\circ} \mathrm{CA}$, and the ignition sequence of the number 6 cylinder is at $390^{\circ} \mathrm{CA}$. The frequency range of the $\mathrm{ICl}$ component is concentrated around $4000 \mathrm{~Hz}-6700 \mathrm{~Hz}$. Combined with Figure 16, the correlation function of cylinder pressure and cylinder head vibration is good at $4000 \mathrm{~Hz}-5000 \mathrm{~Hz}$, but the correlation function is not good at $5000 \mathrm{~Hz}-6700 \mathrm{~Hz}$. Thus, it can be considered that the IC1 component is mainly the combustion noise. However, it
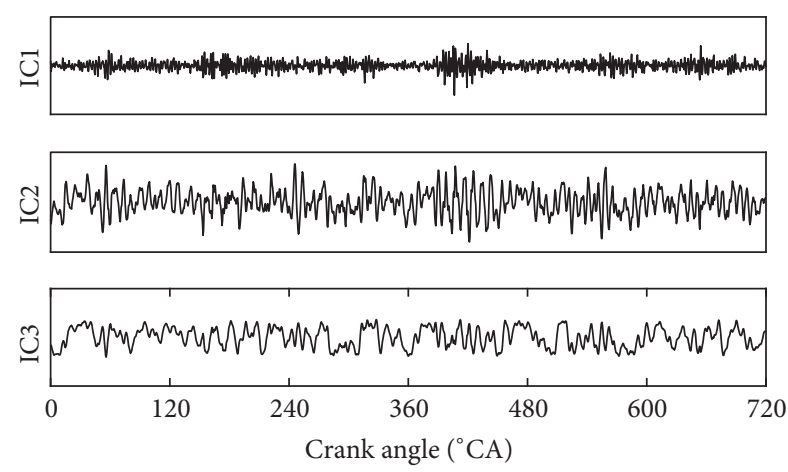

FIgUre 20: Calculation results by the RobustICA.

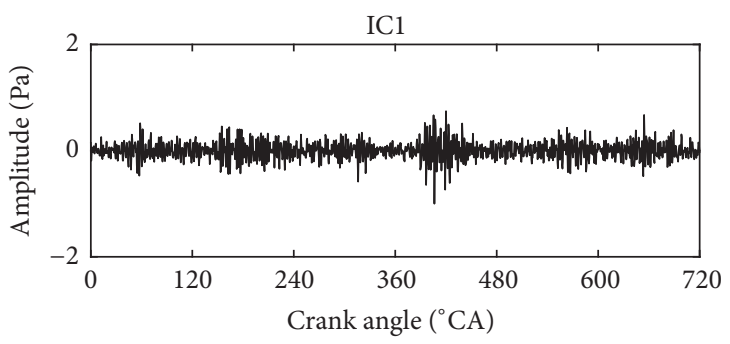

(a) Time domain waveform

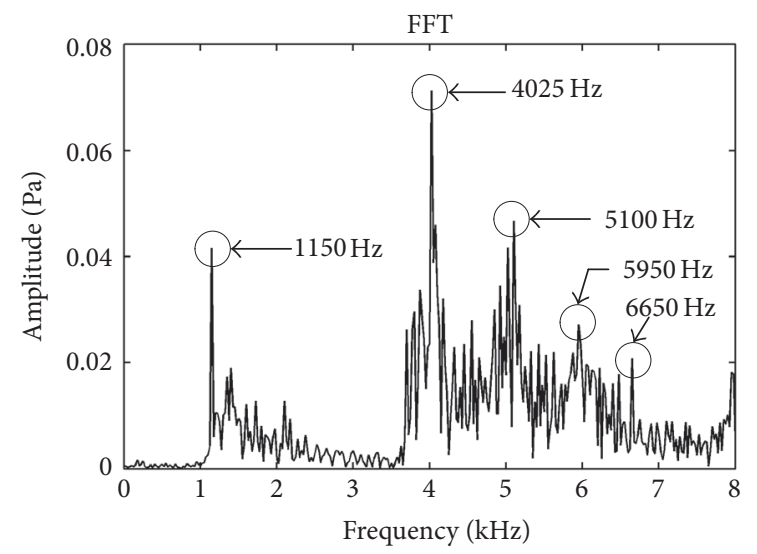

(b) FFT

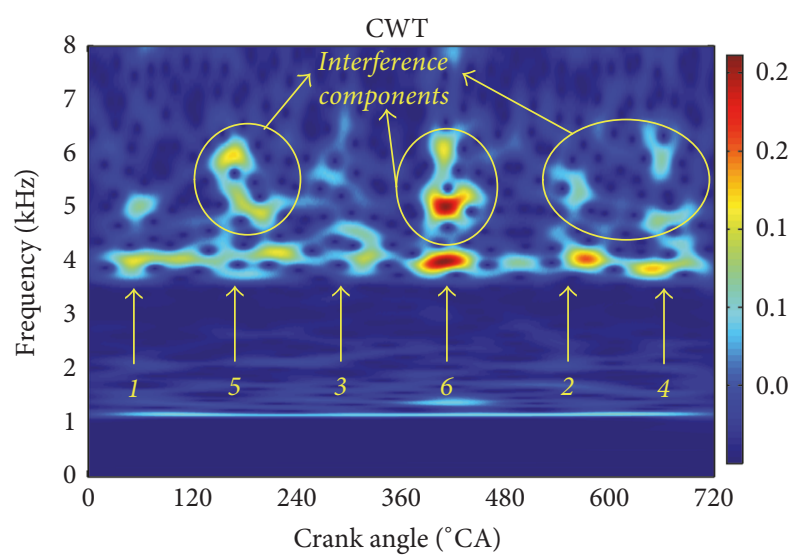

(c) CWT

FIGURE 21: Time domain waveform, FFT, and CWT of IC1 by the EWT-RobustICA method. 


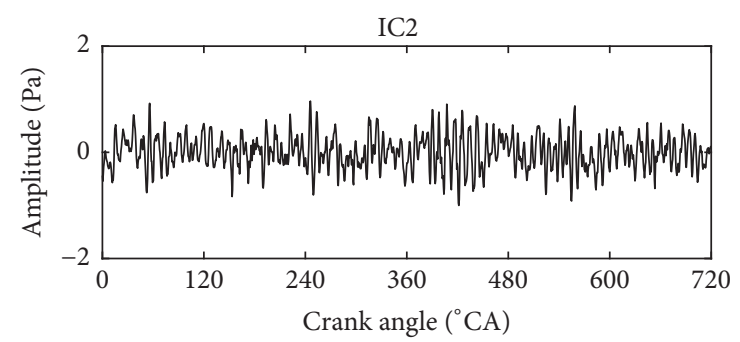

(a) Time domain waveform

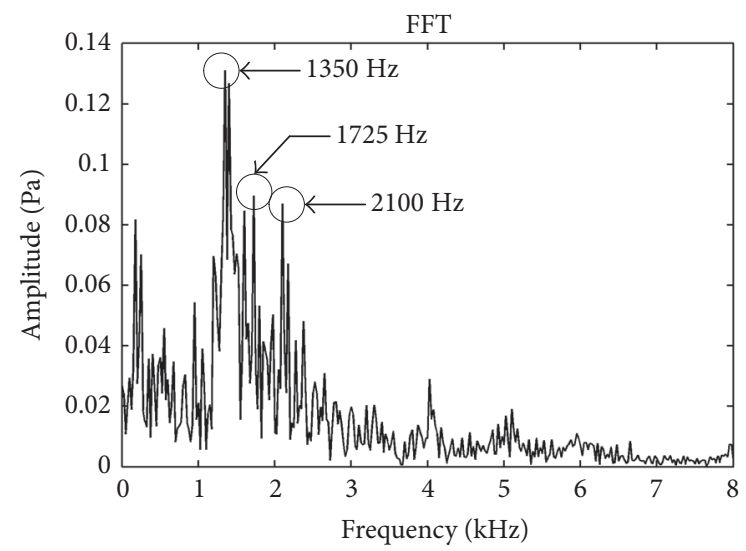

(b) FFT

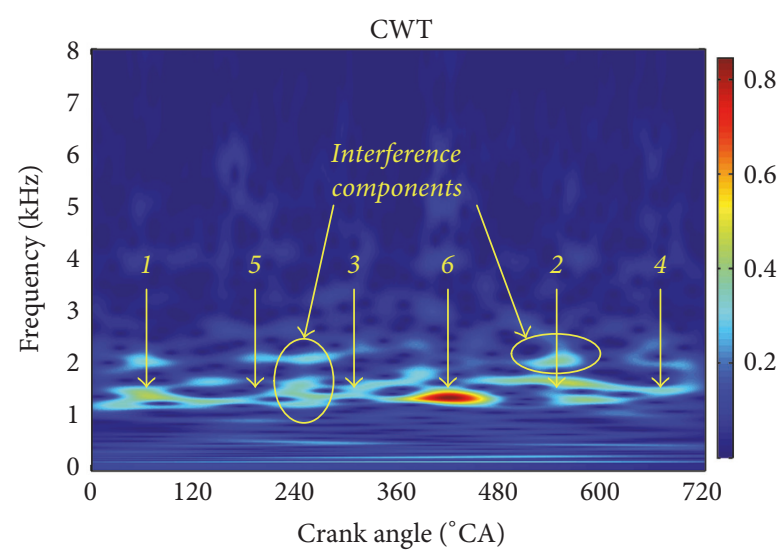

(c) $\mathrm{CWT}$

FIgure 22: Time domain waveform, FFT, and CWT of IC2 by the EWT-RobustICA method.

has many interference components, as shown in the circle in Figure 21(c).

From Figure 22, the amplitude of IC2 component has great change at $390^{\circ} \mathrm{CA}$. It is consistent with the ignition angle of the number 6 cylinder. The frequency of the IC2 component focuses on $1350 \mathrm{~Hz}, 1725 \mathrm{~Hz}$, and $2100 \mathrm{~Hz}$. In the internal combustion engine drag test, the independent piston slap vibration signal is measured. Moreover, the FFT of IC2 and piston slap vibration is shown in Figure 23. From Figure 23, it can be seen that the frequency of piston slap vibration is concentrated at $1700 \mathrm{~Hz}$. But the frequency of IC2 is concentrated at $1350 \mathrm{~Hz}, 1725 \mathrm{~Hz}$, and $2100 \mathrm{~Hz}$. It has some difference with the IC2 component. Combined with Figure 24, the correlation function of IC2 and piston slap

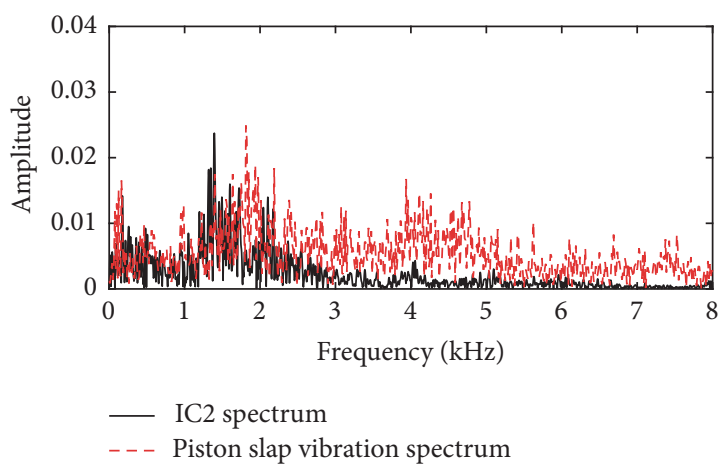

FIGURE 23: FFT of IC2 and piston slap vibration.

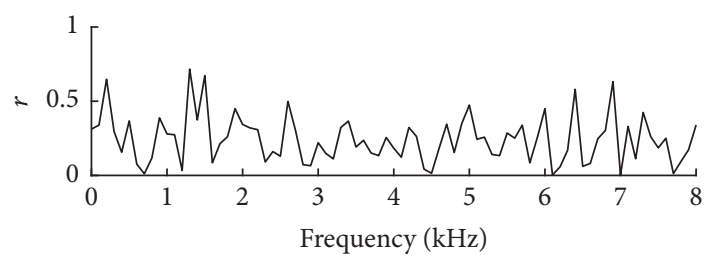

FIGURE 24: Correlation function of IC9 and piston slap vibration.

vibration is not very good. Thus, it can be determined that the IC2 component has some interference components except for the piston slap noise component. It can be seen in the yellow circle in Figure 22(c).

5.3. Comparison Discussion. When adopting the Gammatone-RobustICA method to separate the combustion noise and piston slap noise, the calculation results are shown in Figures 14 and 15. The frequencies of combustion noise and piston slap noise are concentrated at $4025 \mathrm{~Hz}$ and $1725 \mathrm{~Hz}$, respectively. When utilising the EWT-RobustICA method, the separated combustion noise and piston slap noise are shown in Figures 21 and 22. Comparing Figure 14 with Figure 21, it can be seen that there are many other frequency components except for the $4025 \mathrm{~Hz}$ components in Figure 21. Comparing Figure 15 with Figure 22, it can be seen that there are many other frequency components except for the $1725 \mathrm{~Hz}$ components in Figure 22. Moreover, from Figure 17, the IC9 spectrum is consistent with the piston slap vibration spectrum, while in Figure 23, the IC2 spectrum has some difference with the piston slap vibration spectrum. Therefore, compared with the EWT-RobustICA method, the Gammatone-RobustICA method can get more pure combustion noise and piston slap noise. The Gammatone-RobustICA method has a better separation and identification effect than the EWT-RobustICA method.

\section{Conclusions}

(1) In the aspect of the internal combustion engine test, the lead covering method is adopted to wrap the numbers 1-5 cylinders, and only the number 6 cylinder parts are exposed. It can effectively insulate the interference noise from the numbers $1-5$ cylinders. Thus, it is conducive to separating 
and identifying the noise sources of the specified number 6 cylinder.

(2) Inspired by the human auditory system, the Gammatone-RobustICA method is proposed to separate and identify the combustion noise and the piston slap noise. Compared with the EWT-RobustICA method, the proposed Gammatone-RobustICA method has a better separation effect. The separation results obtained by the GammatoneRobustICA method have very fewer other interference components.

\section{Conflicts of Interest}

The authors declare that they have no conflicts of interest.

\section{Acknowledgments}

This work was supported by the National Natural Science Foundation of China, China (Grant no. 51279148).

\section{References}

[1] A. Ruiz-Padillo, D. P. Ruiz, A. J. Torija, and Á. Ramos-Ridao, "Selection of suitable alternatives to reduce the environmental impact of road traffic noise using a fuzzy multi-criteria decision model," Environmental Impact Assessment Review, vol. 61, pp. 8-18, 2016.

[2] X. Zhao, Y. Cheng, L. Wang, and S. Ji, "Real time identification of the internal combustion engine combustion parameters based on the vibration velocity signal," Journal of Sound and Vibration, vol. 390, pp. 205-217, 2017.

[3] E. G. Giakoumis, D. C. Rakopoulos, and C. D. Rakopoulos, "Combustion noise radiation during dynamic diesel engine operation including effects of various biofuel blends: A review," Renewable \& Sustainable Energy Reviews, vol. 54, pp. 1099-1113, 2016.

[4] D. Sachau, S. Jukkert, and N. Hövelmann, "Development and experimental verification of a robust active noise control system for a diesel engine in submarines," Journal of Sound and Vibration, vol. 375, pp. 1-18, 2016.

[5] M. E. Badaoui, J. Danière, F. Guillet, and C. Servière, "Separation of combustion noise and piston-slap in diesel engine - Part I: Separation of combustion noise and piston-slap in diesel engine by cyclic Wiener filtering," Mechanical Systems and Signal Processing, vol. 19, no. 6, pp. 1209-1217, 2005.

[6] C. Servière, J.-L. Lacoume, and M. El Badaoui, "Separation of combustion noise and piston-slap in diesel engine - Part II: Separation of combustion noise and piston-slap using blind source separation methods," Mechanical Systems and Signal Processing, vol. 19, no. 6, pp. 1218-1229, 2005.

[7] Z.-Y. Hao, Y. Jin, and C. Yang, "Study of engine noise based on independent component analysis," Journal of Zhejiang University, vol. 8, no. 5, pp. 772-777, 2007.

[8] X. Wang, F. Bi, C. Liu, X. Du, and K. Shao, "Blind source separation and identification of internal combustion engine noise based on independent component and wavelet analysis," in Proceedings of the 2nd Annual Conference on Electrical and Control Engineering, ICECE 2011, pp. 113-116, China, September 2011.

[9] L. Pruvost, Q. Leclère, and E. Parizet, "Diesel engine combustion and mechanical noise separation using an improved spectrofilter," Mechanical Systems and Signal Processing, vol. 23, no. 7, pp. 2072-2087, 2009.

[10] J. Antoni, N. Ducleaux, G. Nghiem, and S. Wang, "Separation of combustion noise in IC engines under cyclo-non-stationary regime," Mechanical Systems and Signal Processing, vol. 38, no. 1, pp. 223-236, 2013.

[11] J. Zhang, J. Wang, J. Lin et al., "Diesel engine noise source identification based on EEMD, coherent power spectrum analysis and improved AHP," Measurement Science and Technology, vol. 26, no. 9, Article ID 095010, 2015.

[12] F. Bi, L. Li, J. Zhang, and T. Ma, "Source identification of gasoline engine noise based on continuous wavelet transform and EEMD-RobustICA," Applied Acoustics, vol. 100, pp. 34-42, 2015.

[13] N. E. Huang, Z. Shen, S. R. Long et al., "The empirical mode decomposition and the Hilbert spectrum for nonlinear and non-stationary time series analysis," Proceedings of the Royal Society A Mathematical Physical \&amp; Engineering Sciences, vol. 454, pp. 903-995, 1998.

[14] Z. H. Wu and N. E. Huang, "Ensemble empirical mode decomposition: a noise-assisted data analysis method," Advances in Adaptive Data Analysis (AADA), vol. 1, no. 1, pp. 1-41, 2009.

[15] M. Žvokelj, S. Zupan, and I. Prebil, "EEMD-based multiscale ICA method for slewing bearing fault detection and diagnosis," Journal of Sound and Vibration, vol. 370, pp. 394-423, 2016.

[16] J. Gilles, "Empirical wavelet transform," IEEE Transactions on Signal Processing, vol. 61, no. 16, pp. 3999-4010, 2013.

[17] K. Dragomiretskiy and D. Zosso, "Variational mode decomposition," IEEE Transactions on Signal Processing, vol. 62, no. 3, pp. 531-544, 2014.

[18] J. Yao, Y. Xiang, S. Qian, S. Wang, and S. Wu, "Noise source identification of diesel engine based on variational mode decomposition and robust independent component analysis," Applied Acoustics, vol. 116, pp. 184-194, 2017.

[19] Y. Wang, R. Markert, J. Xiang, and W. Zheng, "Research on variational mode decomposition and its application in detecting rub-impact fault of the rotor system," Mechanical Systems and Signal Processing, vol. 60-61, pp. 243-251, 2015.

[20] Z. Li, J. Chen, Y. Zi, and J. Pan, "Independence-oriented VMD to identify fault feature for wheel set bearing fault diagnosis of high speed locomotive," Mechanical Systems and Signal Processing, vol. 85, pp. 512-529, 2017.

[21] M. Zhang, Z. Jiang, and K. Feng, "Research on variational mode decomposition in rolling bearings fault diagnosis of the multistage centrifugal pump," Mechanical Systems and Signal Processing, vol. 93, pp. 460-493, 2017.

[22] D. Wang L, G. Brown J, and C. Darwin, Computational Auditory Scene Analysis: Principles, Algorithms, and Applications, IEEE Press, 2008.

[23] X.-Z. Zhang, B. W. Ling, C. K. Li, and N. C. Leung, "Optimal design of continuous time irrational filter with a set of fractional order gammatone components via norm relaxed sequential quadratic programming approach," Digital Signal Processing, vol. 64, pp. 28-40, 2017.

[24] S. Tabibi, A. Kegel, W. K. Lai, and N. Dillier, "Investigating the use of a Gammatone filterbank for a cochlear implant coding strategy," Journal of Neuroscience Methods, vol. 277, pp. 63-74, 2017.

[25] H. Yin, V. Hohmann, and C. Nadeu, "Acoustic features for speech recognition based on Gammatone filterbank and instantaneous frequency," Speech Communication, vol. 53, no. 5, pp. 707-715, 2011. 
[26] E. C. Smith and M. S. Lewicki, "Efficient auditory coding," Nature, vol. 439, no. 7079, pp. 978-982, 2006.

[27] Q. Zhou, Y. Wang, L. Yi, Z. Tan, and Y. Jiang, "Multisensory Interplay Within Human Auditory Cortex: New Evidence from Intraoperative Optical Imaging of Intrinsic Signal," World Neurosurgery, vol. 98, pp. 251-257, 2017.

[28] P. Sun, D. Fox, K. Campbell, and J. Qin, "Auditory fatigue model applications to predict noise induced hearing loss in human and chinchilla," Applied Acoustics, vol. 119, pp. 57-65, 2017.

[29] S. Strahl and A. Mertins, "Analysis and design of gammatone signal models," The Journal of the Acoustical Society of America, vol. 126, no. 5, pp. 2379-2389, 2009.

[30] F. Meriem, H. Farid, B. Messaoud, and A. Abderrahmene, "New front end based on multitaper and gammatone filters for robust speaker verification," Lecture Notes in Electrical Engineering, vol. 411, pp. 344-354, 2017.

[31] C. Chenot and J. Bobin, "Blind separation of sparse sources in the presence of outliers," Signal Processing, vol. 138, pp. 233-243, 2017.

[32] A. Hyvärinen, "Fast and robust fixed-point algorithms for independent component analysis," IEEE Transactions on Neural Networks and Learning Systems, vol. 10, no. 3, pp. 626-634, 1999.

[33] V. Zarzoso and P. Comon, "Robust independent component analysis by iterative maximization of the kurtosis contrast with algebraic optimal step size," IEEE Transactions on Neural Networks and Learning Systems, vol. 21, no. 2, pp. 248-261, 2010.

[34] P. Di Lena and L. Margara, "Optimal global alignment of signals by maximization of Pearson correlation," Information Processing Letters, vol. 110, no. 16, pp. 679-686, 2010.

[35] N. Dolatabadi, B. Littlefair, M. De La Cruz, S. Theodossiades, S. J. Rothberg, and H. Rahnejat, "A transient tribodynamic approach for the calculation of internal combustion engine piston slap noise," Journal of Sound and Vibration, vol. 352, Article ID 12449, pp. 192-209, 2015. 


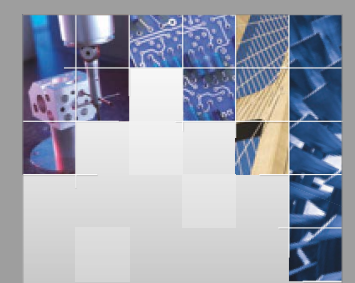

\section{Enfincering}
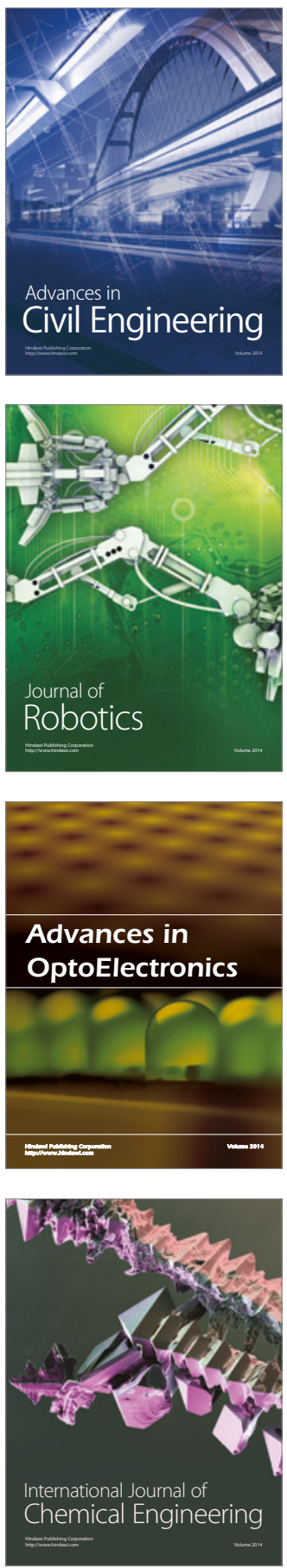

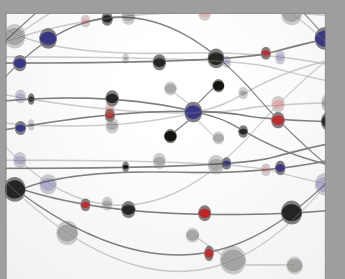

The Scientific World Journal

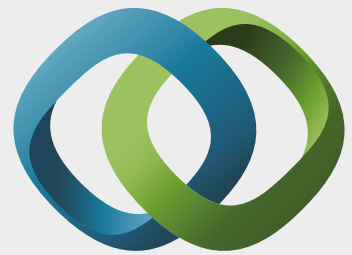

\section{Hindawi}

Submit your manuscripts at

https://www.hindawi.com
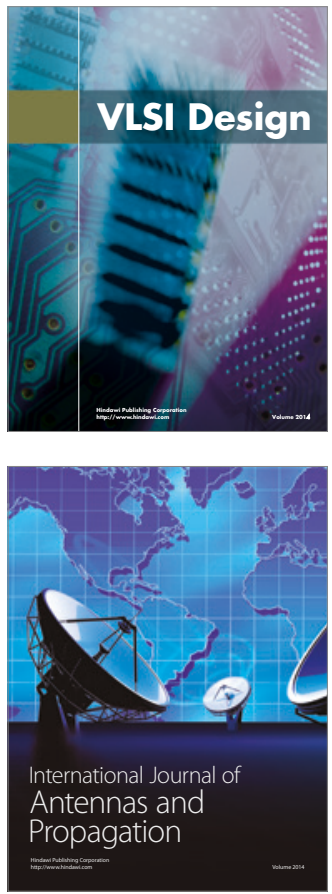

\section{Rotating}

Machinery
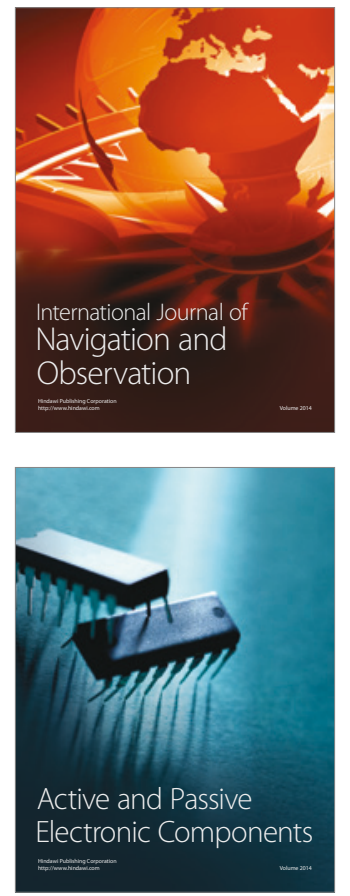
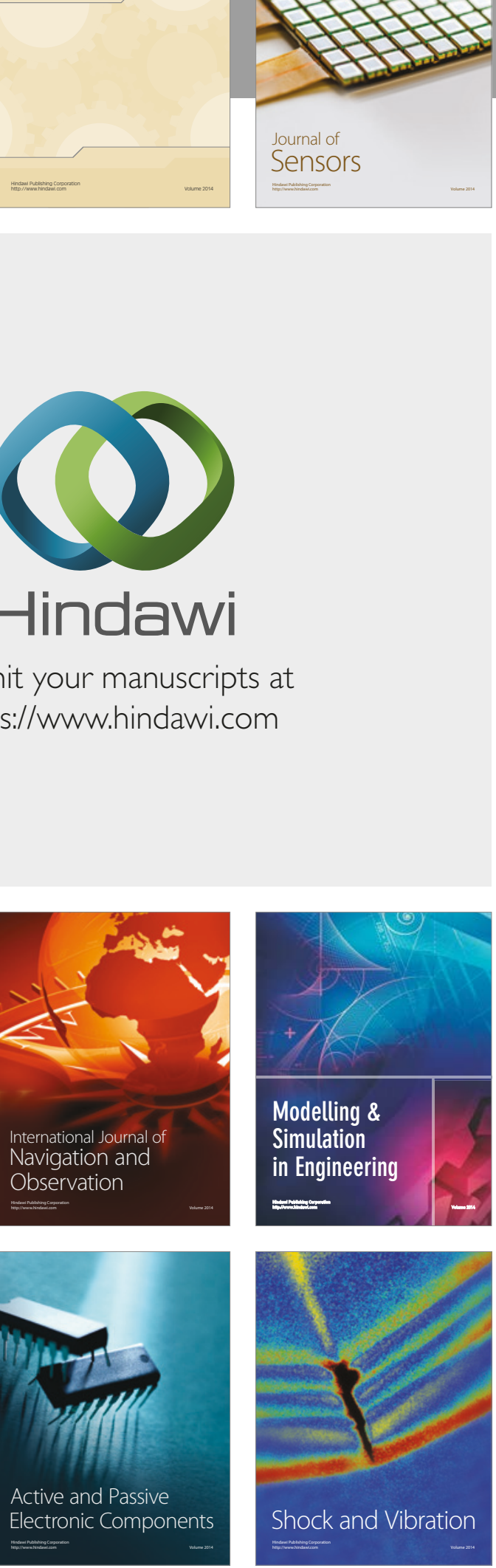
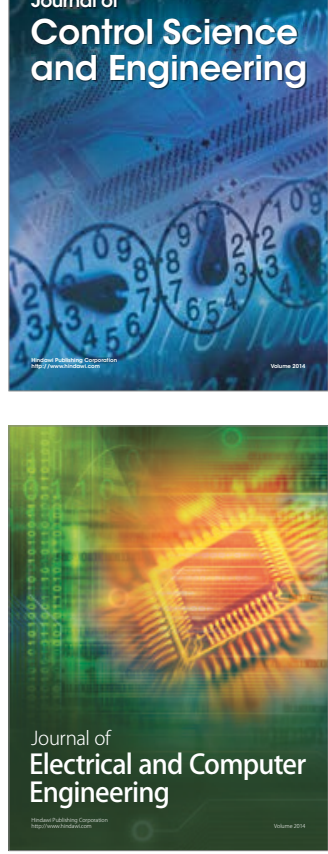

Distributed

Journal of

Control Science

and Engineering
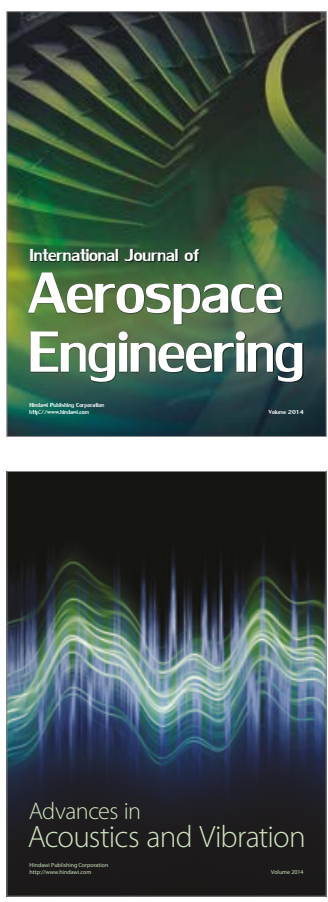

Sensor Networks 